\title{
PLANEJAMENTO E CONTROLE DA PRODUÇÃO DE HAVAIANAS: UM ESTUDO DE CASO NA ALPARGATAS DE CAMPINA GRANDE/PB
}

\section{PRODUCTION PLANNING AND CONTROL OF HAWAIIAN: A CASE STUDY IN ALPARGATAS OF CAMPINA GRANDE/PB}

\author{
Jaqueline Guimarães Santos ${ }^{1}$ \\ ${ }^{1}$ Universidade Federal de Pernambuco - UFPE - Recife - Brasil \\ jsantos.adm@gmail.com
}

\begin{abstract}
Resumo
As recentes mudanças econômicas, políticas, sociais e ambientais tem influenciado sobre os sistemas de produção, levando as organizações a repensar sua forma de organização do trabalho. Diante disso, o planejamento e controle da produção (PCP) estão presentes para responder, de forma mais rápida e precisa, tais mudanças. Nesse sentido, o objetivo desse estudo é descrever e analisar a função Planejamento, Programação Controle e Produção utilizado por uma indústria do setor calçadista para a fabricação de havainas localizada em Campina Grande - PB. O estudo é caracterizado como exploratória e descritiva conduzida sob a forma de estudo de caso. Os dados foram coletados através de entrevista semiestruturada junto ao analista de produção da empresa e complementas com dados secundários e a observação participante na indústria. Os resultados revelam que o PCP desenvolvido pela empresa estabelece um planejamento que possibilita um fluxo contínuo de materiais, pessoas e informações, capazes de alimentar esse sistema, de forma a atender os objetivos estratégicos da organização.
\end{abstract}

Palavras-chave: planejamento; controle da produção; estratégia.

\section{Introdução}

Até meados da década de 90 , as organizações estavam preocupadas apenas com fatores econômicos, ou seja, na redução de custos e o aumento da eficiência. Contudo, as mudanças ocorridas no ambiente, fizeram com que as empresas repensassem sua forma de organizar o trabalho, de modo que fatores políticos, sociais, institucionais e ambientais devem ser levados em consideração no planejamento de suas atividades.

Nesse contexto, podemos enumerar como uma mudança marcante para essa época o grande desenvolvimento tecnológico ocorrido em termos de máquinas, sistemas de informação, automação, robótica, telecomunicações, entre outros, que tornaram possível um planejamento e controle mais eficiente das operações, como o desenvolvimento de novas formas de gestão da produção.

Nesse sentido, torna-se imprescindível que as organizações busquem a modernização e/ou adequação ao novo contexto produtivo por diferentes caminhos, seja pela via tecnológica, seja pela 
via gerencial, a fim de solucionar os problemas de gestão, assim como melhorar o controle dos recursos envolvidos na produção e nos objetivos de desempenho organizacionais, quais sejam: qualidade, rapidez, confiabilidade, flexibilidade e custo.

Desse modo, o novo ambiente competitivo levou as empresas a adotar estratégias de produção que, genericamente, "são abordagens comuns para organizar a função produção que têm sido observadas por serem adotadas em diferentes tipos de organizações" (SLACK et al, 2008, p. 24).

Para responder de forma mais rápida e precisa as mudanças, tanto internas como externas à organização, as empresas realizam o planejamento e controle da produção (PCP), no qual suas atividades são desenvolvidas por um departamento de apoio à produção, sendo este responsável pela coordenação e aplicação dos recursos produtivos de forma a atender, da melhor maneira possível, aos planos estabelecidos em níveis estratégico, tático e operacional.

Segundo Corrêa et al (2007), o Planejamento e Controle da Produção é o conjunto de sistemas de informações que servem de apoio à tomada de decisões táticas e operacionais, relacionadas às questões logísticas de: "o que" produzir e comprar, "quanto" produzir e comprar, “quando" produzir e comprar e, “com quais recursos" produzir (MOURA JÚNIOR, 2006).

Dessa maneira, a abordagem do planejamento e controle de produção é focada na otimização dos controles de fluxos de informações, materiais e pessoas, no qual para atingir seus objetivos, administra informações vindas de diversas áreas do sistema produtivo, que de forma direta ou indireta, alimenta esse sistema. Assim sendo, as organizações atuam na busca do aperfeiçoamento de seus Sistemas de Administração da Produção, considerados por Giannesi e Correia (1993) como o "coração" dos processos produtivos.

Destaca-se também a programação da produção como requisito essencial para que o processo de planejamento e controle de bens e serviços seja realizado conforme o previsto. Portanto, este processo envolve o planejamento, programação e controle da produção (PPCP).

Assim sendo, o presente estudo tem por objetivo descrever e analisar a função Planejamento, Programação Controle e Produção utilizada por uma indústria do setor calçadista para a fabricação de havaianas localizada em Campina Grande - PB.

Para o alcance do objetivo proposto, este trabalho está organizado em cinco seções. Além da presente introdução, a segunda seção apresenta o referencial teórico, evidenciado conceitos importante para o entendimento dessa temática, já a terceira seção os aspectos metodológicos para a realização da pesquisa. Em seguida, verifica-se a análise e apresentação dos resultados e, por fim, a quinta seção trata das considerações finais. 


\section{Referencial teórico}

Nessa seção iremos evidenciar os aportes teóricos utilizados para fundamentar a realização da pesquisa. Inicialmente trata-se de uma visão geral sobre sistemas produtivos, depois uma discussão sobre o Planejamento, Programação e Controle da Produção (PCP), e em seguida sobre o papel da função PCP nas empresas.

\subsection{Sistemas produtivos}

Antes de iniciar a discussão propiamente dita sobre o Planejamento e Controle da Produção (PCP) é importante conceituar a função produção, esta é entendida como sendo um processo de transformação que produz bens ou serviços, ou um misto dos dois, conforme mostra a Figura 1 abaixo.

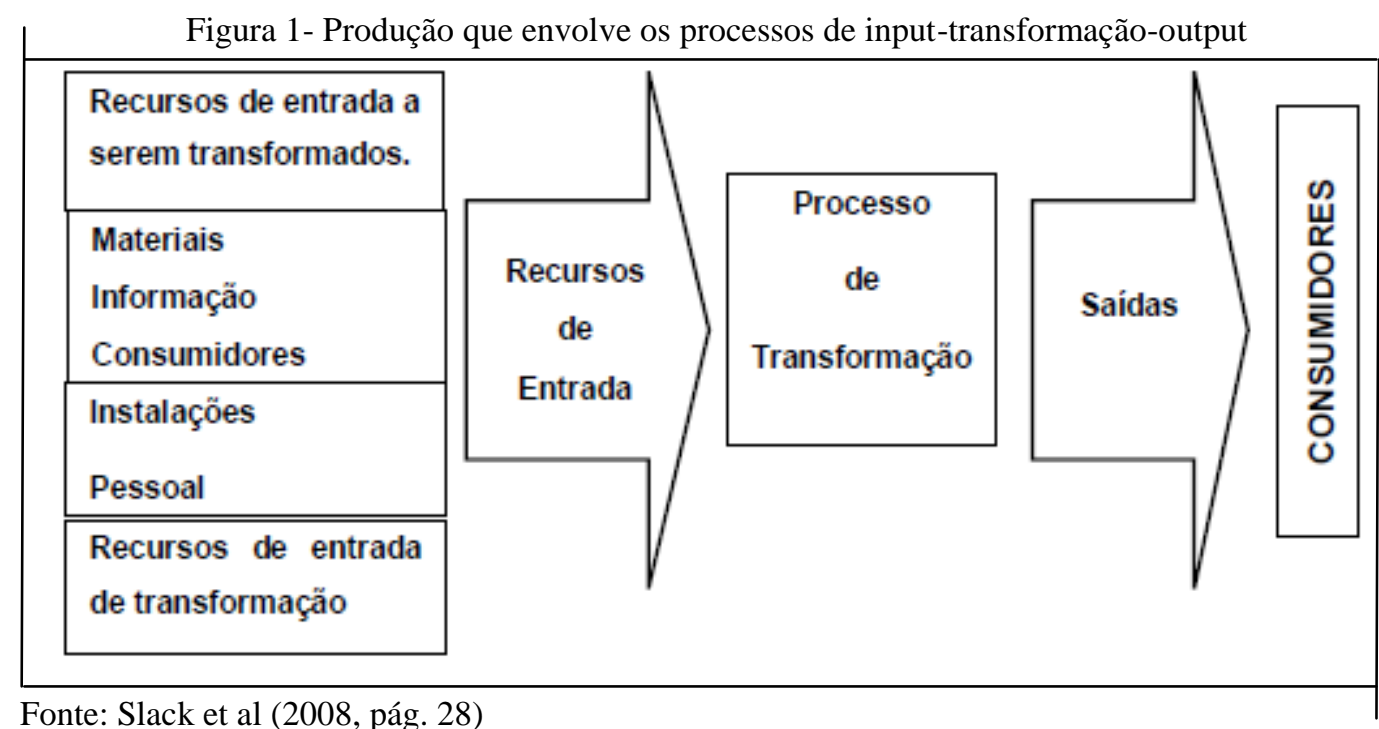

É perceptível que a função Produção em uma organização envolve diversos aspectos que são da responsabilidade do Planejamento e Controle da Produção - PCP (inputs e outputs) que são fundamentais para que a empresa obtenha sucesso organizacional. Há uma crescente preocupação com o gerenciamento da produção por parte das empresas, já que a produção envolve várias ações que de certa forma, se bem gerenciadas, evitam perdas por parte dos processos resultando em maiores receitas e, por conseguinte, maiores lucros.

Diante disso, podemos enumerar algumas ações que contribuiram para uma melhor gestão da produtividade, quais sejam: a gestão da eficiência dos equipamentos, profissionais relacionados com a implantação do 5S, melhorias em termos dos atuais tempos de preparação de máquinas, gestão da qualidade, analistas de Processo que tratam da questão da melhoria dos tempos de processamento das máquinas, desenvolvimento de profissionais vinculados com a problemática da 
segurança do trabalho e da Ergonomia, dentre outras que estão ligadas ao sistema produtivo de qualquer empresa, conforme podemos verificar na figura 2 abaixo.

Figura 2 - Ações de gerenciamento da produção

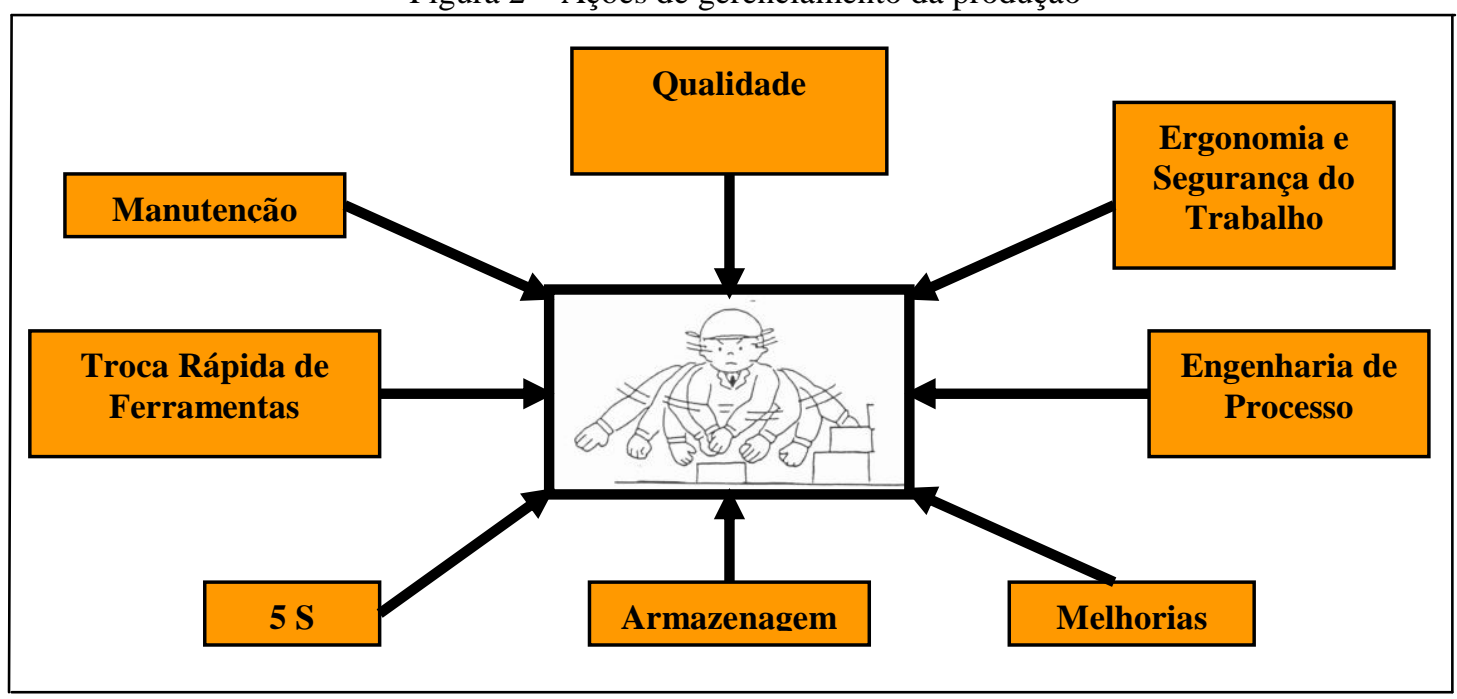

Fonte: Autoria própria (2011)

Como podemos observar, a função produção envolve diversas atividades, no qual devem estar bem alinhadas e gerenciadas, de modo a alcançar os objetivos de desempenho organizacionais, produzindo produtos de qualidade e no tempo programado, de forma que a empresa possa atender as demandas e expectativas dos seus clientes.

Nesse contexto, o Planejamento e Controle da Produção (PCP) desenvolve função importante no gerenciamento das atividades de produção a partir do que foi planejado no nível estratégico, passando para os demais níveis, buscando-se alinhar suas atividades a fim de alcançar os objetivos estratégicos também da organização.

\subsection{Planejamento e controle da produção (PCP)}

O Planejamento e Controle da Produção (PCP) é um departamento de apoio responsável pela coordenação e aplicação dos recursos produtivos de forma a atender, da melhor maneira possível, aos planos estabelecidos em níveis estratégico, tático e operacional.

Para atingir seus objetivos, o PCP administra informações vindas de diversas áreas do sistema produtivo. Da Engenharia do Produto são necessárias informações contidas nas listas de materiais de desenhos técnicos, da Engenharia de Processo os roteiros de fabricação e os lead times, no Marketing buscam-se os planos de vendas e pedidos firmes, a Manutenção fornece os planos de manutenção, Compras/Suprimentos informa as entradas e saídas dos materiais em estoques, dos Recursos Humanos são necessários os programas de treinamento, Finanças fornece o plano de investimentos e o fluxo de caixa, entre outros relacionamentos. Dessa forma, fica evidente a relação que o PCP tem com praticamente todas as funções deste sistema. 
O Planejamento e controle consistem em uma "função de apoio de coordenação das várias atividades de acordo com os planos de produção, de modo que os programas preestabelecidos possam ser atendidos nos prazos e quantidades" (RUSSOMANO, 2000, p.49). Bonney (2008) acrescenta que a função de PPC e seus sistemas integrados direcionam o planejamento e controle de forma que a empresa possa detectar efetivamente as exigências do seu processo produtivo. Sendo assim, pode-se constatar que cabe a esta função assegurar o cumprimento dos objetivos de desempenho organizacionais a partir da aplicação eficiente dos recursos de produção.

Para o alcance dos objetivos, as atividades do PCP são exercidas nos três níveis hierárquicos de planejamento e controle das atividades produtivas de um sistema de produção, conforme podemos observar na tabela abaixo.

\begin{tabular}{|c|c|}
\hline Nível & Atividades do PCP \\
\hline Estratégico & $\begin{array}{c}\text { São definidas as políticas estratégicas de longo prazo da empresa, o PCP } \\
\text { participa da formulação do Planejamento Estratégico da Produção, gerando um } \\
\text { plano de produção. }\end{array}$ \\
\hline Tático & $\begin{array}{c}\text { São estabelecidos os planos de médio prazo para a produção, o PCP } \\
\text { desenvolve o Planejamento Mestre da Produção, obtendo o Plano Mestre da } \\
\text { Produção (PMP). }\end{array}$ \\
\hline Operacional & $\begin{array}{l}\text { Estão preparados os programas de curto prazo de produção e realizado o } \\
\text { acompanhamento dos mesmos, o PCP prepara a programação da produção } \\
\text { administrando estoques, seqüenciado, emitindo e liberando as ordens de } \\
\text { compras, fabricação e montagem, bem como executa o acompanhamento e } \\
\text { controle da produção. }\end{array}$ \\
\hline
\end{tabular}

Fonte: Autoria própria (2012)

Podemos averiguar, portanto, que o PCP desenvolve atividades nos três níveis hierárquicos e que a partir do que foi planejado no nível estratégico será planejado nos níveis subsequentes, de forma mais detalhada iremos elucidar as atividades do PCP em cada nível.

\subsubsection{Planejamento estratégico da produção}

Refere-se a uma função de longo prazo, a qual possui uma estreita relação com o planejamento estratégico da organização, envolvendo aspectos mais genéricos relacionados à produção, como por exemplo, a definição estratégica da produção, estabelecimento do plano de produção em função do plano de vendas, dentre outros aspectos.

Tubino (2000) corrobora quando afirma que o planejamento de produção consiste em estabelecer um plano de produção para determinado período (longo prazo) segundo as estimativas de vendas e a disponibilidade de recursos financeiros e produtivos... (TUBINO, 2000). A estimativa de vendas serve para prever os tipos e quantidades de produtos que se espera vender no horizonte de planejamento estabelecido. A capacidade de produção é o fator físico limitante do processo produtivo, e pode ser incrementada ou reduzida, desde que planejada a tempo, pela edição de recursos financeiros. O plano de produção gerado é pouco detalhado, normalmente trabalha com 
famílias de produtos, tendo como finalidade possibilitar a adequação dos recursos produtivos à demanda esperada dos mesmos.

\subsubsection{Planejamento-mestre da produção}

Compreendem as funções de médio prazo e corresponde principalmente aquelas atividades que se relacionam com a definição do plano mestre de produção. De acordo com Tubino (2000), consiste em estabelecer um plano mestre de produção (PMP) de produtos finais, detalhando em médio prazo, período a período, a partir de um plano de produção, com base nas previsões de vendas de médio prazo ou nos pedidos em carteira já confirmados.

O plano de produção considera família de produtos, o PMP especifica itens finais que fazem parte dessas famílias. Com base no estabelecimento do PMP, o sistema produtivo passa a assumir compromissos de fabricação e montagens dos bens e serviços. Ao executar o plano mestre da produção e gerar um PMP inicial, o PCP deve analisá-lo quanto às necessidades de recursos produtivos quanto à finalidade de identificar possíveis gargalos que possam inviabilizar esse plano quando de sua execução em curto prazo.

\subsubsection{Programação da produção}

Referem-se às atividades de curto prazo e relacionam com o planejamento operacional do PCP com base no PMP e nos registros de controle de estoques. Segundo Tubino (2000) a Programação da produção estabelece em curto prazo quando e quanto comprar, fabricar ou montar de cada item necessário à composição dos produtos finais. São dimensionadas e emitidas ordens de compras para os itens comprados, ordens de fabricação para os itens fabricados internamente, e ordens de montagem para as submontagens intermediárias e montagem final dos produtos definidos no PMP.

Em função da disponibilidade dos recursos produtivos, a programação da produção encarrega-se de fazer o sequenciamento das ordens emitidas, de forma a aperfeiçoar a utilização dos recursos. Dependendo do sistema de produção empregado pela empresa (puxado ou empurrado), a programação da produção enviará as ordens a todos os setores responsáveis (empurrando) ou apenas à montagem final (puxando).

\subsubsection{Acompanhamento e controle da produção}

É por meio do acompanhamento e controle da produção que se busca garantir que o programa de produção emitido seja executado conforme planejado inicialmente. Quanto mais rápido os problemas forem identificados, mais efetivas serão as medidas corretivas visando o cumprimento do programa de produção. O acompanhamento e controle de produção estão 
encarregados de coletar dado (índices de defeitos, horas/máquinas e horas/homens consumidas, consumo de materiais, índice de quebra de máquinas etc.) para outros setores do sistema produtivo.

De forma geral, a função do planejamento e controle é conciliar o fornecimento de produtos e serviços com a demanda. Assim, caberá ao PCP definir as quantidades de produtos a ser produzido, manter o controle sobre os estoques, emitir ordens de produção programadas, movimentá-las e, finalmente, fazer seu acompanhamento na quantidade, tempo e qualidade exigida.

Para tanto, requer o reconhecimento das características dos produtos serviços a serem executados, tais como, a natureza da demanda e suprimento. As diferenças encontradas em cada uma delas fazem com que os responsáveis pelo PCP alterem a forma que devem planejar e controlar suas atividades. Isto ocorre porque quanto mais incerta for à demanda, seja ela dependente ou independente, mais difícil será a definição do planejamento e mais rigoroso deverá ser o seu controle.

A complexidade das atividades de PCP resultou no desenvolvimento de ferramentas eficazes à gestão da produção. Entre as mais difundidas encontramos, o MRP ou ERP, JIT, Kanban, entre outros. Sabe-se que esses sistemas, quando bem aplicados, ampliam a capacidade operacional e consequentemente a produtividade organizacional. Segundo Pires (1995), as atividades de planejamento e controle da produção podem ser atualmente implementadas e operacionalizadas através do auxílio de, pelo menos, três sistemas, quais sejam: MRP II, JIT e OPT.

O MRP (material requirement planning) consiste em um planejamento das necessidades de material surgido com a necessidade de se planejar o atendimento da demanda dependente tanto na produção de bens tangíveis como serviços. Conforme Cavalcanti e Moraes (1998, p.5) tal sistema é empregado "para planejar a capacidade produtiva, isto é, para calcular os recursos humanos e fabris necessários à manufatura das partes componentes ao produto final”.

Atualmente, este sistema vem sendo frequentemente substituído pelo MRP II (manufacturingm resources planning) ou ERP (enterprise resource planning). Segundo Laurindo e Mesquita (2008, p.335) “os ERP caminharam na direção de tornarem-se cada vez mais sistemas integrados de gestão empresarial (um produto focado em TI), afastando-se da proposta inicial dos MRP”.

A aplicação desses sistemas (MRP, MRP II, ERP) torna-se conveniente na medida em que se torna um instrumento de planejamento, auxilia na tomada de decisão através da projeção de demandas, fornece conhecimento detalhado sobre o custo embutido em cada produto e ainda reduz a influência dos sistemas informais, ou seja, conhecimentos importantes armazenados em indivíduos específicos (MARTINS e LAUGENI, 1999).

Como foram observados, esses sistemas apresentam aspectos relativos às formas de planejamento citadas anteriormente. Contudo, a preferência para sua aplicação são as fábricas que 
tenham como estrutura produtos; principalmente aquelas cuja demanda são dependentes para emissão de ordem (RUSSOMANO, 2000).

A técnica japonesa do Just-in-time (JIT), por sua vez, foi desenvolvida para combater todas as atividades que consomem recursos e que não agregam valor ao produto ou serviço. Em outras palavras, destaca-se que tal sistema "visa administrar a manufatura de forma simples e eficiente, otimizando o uso dos recursos de capital, equipamento e mão de obra" (ALVES, 2006, p.3). Por esta razão, a ênfase dada a esta técnica como apoio à função de planejamento e controle.

Atualmente, o JIT é considerado uma filosofia gerencial que além de eliminar desperdícios, distribui e coloca o componente certo, no lugar certo e na hora certa, propiciando desta forma, estoques pequenos, custos mais baixos e melhor qualidade do que os sistemas convencionais de qualidade.

Segundo Slack, Chambers e Johnston (2002), o Just-in-time requer alta performance em todos os objetivos de desempenho da produção. Para isso, faz-se necessário a ocorrência de um alto grau de qualidade, a fim de evitar distúrbios produtivos e propiciar a rapidez no fluxo de matérias, a confiabilidade de equipamentos e processos, bem como a flexibilidade no processo produtivo, resultando deste modo na redução de custos.

Alves (2006) defende a existência de três ideias básicas que fundamenta o desenvolvimento do JIT. A primeira delas consiste na integração e otimização do processo de manufatura desde a concepção a elaboração do projeto de um novo produto. A segunda delas se refere ao processo de melhoria contínua, também conhecido como Kaizen. E finalmente, encontra-se a capacidade da organização em entender e responder às necessidades dos seus clientes seja por meio dos padrões de qualidade dos produtos, dos prazos destinados à entrega, assim como o custo total do produto para o cliente.

O JIT é composto de várias ferramentas, técnicas e elementos, entre elas, Programa Mestre (Master Plan), Kanban, tempos de preparação (Setuptime), layout apropriado, alta qualidade e fornecedores integrados com o seu processo produtivo. Sua implantação, no entanto, não está limitada às fronteiras organizacionais, haja vista que as diretrizes para alcançá-lo envolvem todos os seus membros, fornecedores, clientes e processos de produção.

Nesse contexto, compreende que atualmente a atividade do PCP depende de muitos fatores e que seus objetivos devem estar alinhados aos objetivos estratégicos competitivos da organização, de modo que a redução de custos, entretanto, passa a ser acompanhada por objetivos de desempenho antes deixado em segundo plano, nos quais se cita a qualidade, rapidez, confiabilidade e flexibilidade. 


\subsubsection{O papel da função PCP}

O Papel da função PCP é apoiar sua estratégia de produção a partir da estratégia organizacional, para isso deve desenvolver seus recursos para que forneçam as condições necessárias para permitir que a empresa atinja seus objetivos organizacionais. Se um fabricante microcomputadores decidiu ser o primeiro no mercado com novos produtos inovadores, sua função produção precisa ser capaz de enfrentar as mudanças de inovação contínua exigidas (SLACK, et al, 2008).

Deve desenvolver ou comprar processos que sejam flexíveis o suficiente para fabricar novos produtos ou serviços, organizando e treinando funcionários para que entendam como os produtos estão mudando e fazer as mudanças necessárias na produção. Deve desenvolver relacionamento com os fornecedores que ajudem a responder rapidamente no fornecimento de novos componentes, quanto melhor a produção fizer essas coisas, mais apoio estará dando para a estratégia competitiva da empresa (HARRISON, 1997).

$\mathrm{Na}$ busca pela operacionalização do estudo, a próxima seção aborda os procedimentos metodológicos utilizados para a concretização do objetivo proposto no sentido de demonstrar como foram desenvolvidas as conclusões da pesquisa.

\section{Procedimentos metodológicos}

\subsection{Características da pesquisa}

O presente estudo foi caracterizado, quanto aos fins, como pesquisa exploratória pelo fato de caracterizar o problema a fim de defini-lo melhor, e promover critérios de compreensão de dados e informações, e descritiva, na medida em que objetiva descrever as características de determinado fenômeno.

Quanto à meio optou-se por um estudo de caso, visto que este tipo, segundo Vergara (2010) “é circunscrito a uma ou poucas unidades, entendidas essas como uma pessoa, uma família, um produto, uma empresa, um órgão público, uma comunidade ou mesmo um país, tem um caráter de profundidade e detalhadamente, e pode ou não ser realizado no campo"

Em se tratando da abordagem, a pesquisa pode ser considerada como de ordem qualitativa, no qual os dados da pesquisa de campo foram obtidos a partir de observação não participante e entrevista junto ao analista de produção da empresa.

A pesquisa de campo foi realizada em uma indústria calçadista de grande porte localizada no estado da Paraíba, limitando-se ao setor de PCP da referida empresa. O presente artigo também fez uso da pesquisa bibliográfica como suporte à pesquisa de campo, uma vez que foi dada ênfase aos registros já publicados, como por exemplo, livros, artigos científicos, teses e dissertações. 
A análise e tratamento dos dados foram apoiados qualitativamente e apresentados através de linguagem discursiva. Quanto ao tratamento, aplicou-se o método de análise de conteúdo. Neste sentido, foi realizada leitura comparativa das citações do sujeito de pesquisa, bem como, sua ordenação, classificação e categorização. Os resultados obtidos com a entrevista foram avaliados paralelamente às anotações realizadas durante a fase de observação.

\subsection{Contexto da pesquisa}

\subsubsection{Caracterização do arranjo produtivo local de couro e calçados}

O Arranjo Produtivo de Calçados no Brasil tem sua história remontada ao início do processo de industrialização do país, tendo em vista os seus baixos custos e a extensão territorial da nação, que possibilitou a eclosão de vários pólos calçadistas em estados diversos.

Neste contexto, de acordo com a Associação Brasileira das Indústrias de Calçados ABICalçados (2003), a indústria brasileira de calçados é responsável pela produção de aproximadamente 600 milhões de pares de calçados/ano, do qual cerca de 190 milhões foram destinados à exportação no ano de 2001, colocando o setor calçadista como um dos mais importantes da economia brasileira pelo seu volume de produção e pela sua capacidade de gerar emprego e renda, bem como pela sua expressiva participação na demanda de exportação do país.

Atualmente, o Brasil exporta para cerca de 70 países, gerando uma produção de aproximadamente US\$ 1,5 bilhão por ano. De acordo com Navarro (2006), os principais pólos produtores nacionais estão localizados nos estados do Rio Grande do Sul, São Paulo, Santa Catarina, Minas Gerais, Bahia, Paraíba e Ceará.

$\mathrm{Na}$ Paraíba, o setor coureiro-calçadista e afins vem se consolidando como um grande indutor no desenvolvimento do Estado, por sua capacidade produtiva instalada, formal e informal, principalmente, nos municípios de Campina Grande, João Pessoa, Santa Rita e Patos, conforme dados da Central de Informações para Sistemas Agroindustriais - CENINSA (2002).

Em 2007, a Paraíba ganhava manchete dos jornais como o $3^{\circ}$ maior produtor de calçados do país, que, de acordo com o SEBRAE, “dos 700 milhões de pares de calçados produzidos por ano no Brasil, cerca de 200 milhões são fabricados na Paraíba”. Neste contexto, destaca-se o município de Campina Grande/PB, com sua estrutura e condições favoráveis ao desenvolvimento promissor do setor calçadista.

Segundo Kehrle (2004), O surgimento da atividade coureira em Campina Grande/PB iniciou-se no ano de 1923, com a criação de Curtumes na cidade. Sua produção destinava-se inicialmente à confecção de selas, arreios e rédeas para montarias, muito utilizadas no meio rural.

Atualmente, o Arranjo Produtivo Local de Calçados de Campina Grande/PB é composto fundamentalmente por produtores locais, de micro e pequeno porte, de calçados e artefatos de couro 
ou de material sintético, sendo grande parte das empresas de estrutura familiar, característica encontrada, também, na maioria dos outros pólos calçadistas espalhados pelo Brasil.

Insere-se nesse contexto, a Alpargatas S.A. como uma empresa que se diferencia um pouco com as empresas do APL campinense de calçados, pois se caracteriza como de grande porte, exportando suas mercadorias para todo o mundo, sendo a unidade campinense a única produtora de havaianas.

\subsubsection{Caracterização da empresa}

A história está associada à da industrialização e do desenvolvimento do mercado de consumo no Brasil. A experiência em distribuição e manufatura propiciou a diversificação da linha de produtos e o aproveitamento de oportunidades mercadológicas. Foi uma das pioneiras no desenvolvimento de marcas próprias de produtos de consumo, divulgadas com o apoio de campanhas de propaganda e promoção.

A Companhia foi fundada em 1907, na cidade de São Paulo, por investidores de origem britânica, para produzir e vender Alpargatas Roda e outros produtos como lonas e coberturas. Suas ações são listadas em Bolsa de Valores desde 1913.

$\mathrm{Na}$ década de 60, chega ao mercado a Havaianas, a sandália que tem a cara do Brasil, e que todo mundo usa. Nos anos 70, o processo de expansão da Companhia inclui o lançamento da marca Topper e aquisição da marca Rainha, assim como a inauguração de quatro novas fábricas: Natal (RN), Veranópolis (RS), Pouso Alegre (MG) e Mogi Mirim (SP).

O processo de nacionalização do capital completou-se nos anos 80, e a Alpargatas continuou sua expansão inaugurando novas fábricas em Manaus (AM), Campina Grande, João Pessoa e Santa Rita (PB) e Franca (SP), chegando as atuais 7 unidades.

Como podemos observar, a São Paulo Alpargatas apresenta vários centros de produção espalhados por todo o Brasil, de acordo com o seu mix de produtos, tendo em vista que cada localidade apresenta características favoráveis para desenvolver o seu tipo de produto.

No século XXI muitas foram às realizações, os produtos da Alpargatas estão cada vez mais presentes no cotidiano do brasileiro. As sandálias Havaianas completaram 40 anos de prestígio no Brasil, e agora fazem sucesso também no exterior. No segmento para futebol a marca Topper tornou-se líder absoluta, a Rainha recebeu pelo décimo ano consecutivo o prêmio "Top of Mind" como a marca mais lembrada pelos consumidores. Foram ainda relançadas as marcas Conga e Bamba, ícones da década de 60 e 80 que voltam ao mercado de calçados de moda.

Para efeito desse estudo, buscou-se analisar o planejamento programção e controle do sistema produtivo da unidade de Campina Grande, enfatizando principalmente a fabricação de sandálias havaianas, por este ser considerado um produto que detém uma maior fatia de mercado. 


\subsubsection{A unidade campinense de São Paulo Alpargatas}

Campina Grande, cidade situada no alto da serra da Borborema no Estado da Paraíba a 130 km da capital João Pessoa, e grande pólo trabalhista da região Nordeste. Aqui se encontrava uma fábrica de sandálias de material sintético, a BESA (Borracha Esponjosa S.A.), uma fábrica de produtos da marca DUPÉ, que foi adquirida pela São Paulo Alpargatas S.A. em 1985 e assim fundando a unidade fabril $\mathrm{n}^{\circ} 22$ de sua rede de fábricas nesta cidade.

A Unidade campinense é única produtora mundial das sandálias Havaianas. Nela são fabricados oito pares de sandálias Havaianas por segundo, o que dá 105 milhões de pares por ano. Desde que foram lançadas, em 1962, já foram vendidas mais de 2 bilhões de pares das "legítimas" em todo mundo, e hoje ela é líder no mercado brasileiro de sandálias e principal marca da Alpargatas, sendo atualmente a maior fábrica da SPASA, não só em área construída, mas também em lucro.

Logo, políticas de melhorias voltadas à segurança do trabalho, layout, meio ambiente, limpeza, ética profissional e fiscal são imprescindíveis à empresa, que trabalha nesta unidade em três turnos para o complexo produtivo e um turno geral para os setores administrativos.

Nesse sentido, a fábrica possui as seguintes unidades setoriais: RH (Recursos Humanos), PCP (Programação e Controle da Produção), Engenharia Industrial, Engenharia de Manutenção, Produção, Laboratório, CD (Centro de Distribuição), Qualidade e Segurança do Trabalho.

Observa-se que a empresa apresenta diversos departamentos bem definidos para execução das atividades as quais são designadas, no qual soma um total de funcionários de 6.500 (seis mil e quinhentos) sendo 500 (quinhentos) na administração e o restante na produção. A Alpargatas também possui serviços terceirizados, quais sejam: limpeza, transporte, segurança e alimentação.

A unidade campinense da Alpargatas S.A é bastante comprometida com as atividades que desempenham, no qual a cada dia conquistar mais clientes fiéis, já que seus principais objetivo são: agregar valor para o seu negócio, assegurar o crescimento e a perenidade da instituição, remunerar o capital e os investimentos de seus acionistas, promover a satisfação de seus funcionários e colaboradores, atender às necessidades de seus clientes e consumidores, além de contribuir para a solução dos problemas sociais nas comunidades em que atua.

\section{Análise e apresentação dos resultados}

A indústria de calçados pesquisada trabalha com o PPCP, ou seja, planejamento programação e controle da produção, embora a nomenclatura utilizada pelo grupo mantenha-se em PCP. Compete a este setor a elaboração do planejamento estratégico de produção, com base nas estimativas de vendas e informações principalmente advindas da engenharia industrial e engenharia do produto. A partir disso, é feito o plano mestre da produção (PMP) detalhando em médio prazo as 
atividades de produção, e por fim elabora-se a programação da produção com base no PMP e nos registros de controle de estoques, que estabelece em curto prazo, quando e quanto comprar a matéria-prima para posteriormente fabricar os componentes das sandálias e assim ocorrer à montagem da mesma.

Nesse momento, também existe a atividade de controle de produção, ou seja, é feito a verificação se o que foi planejado esta sendo executado para a identificação de possíveis gargalos que comprometam o processo. Caso verifique a ocorrências de falhas, busca-se rapidamente solucionar para que tudo ocorra conforme o planejado.

Nesse contexto, é feito o planejamento e controle de acordo com capacidade instalada, planejamento e controle de estoques, emissão de ordens de fabricação, bem como a elaboração da programação e fazer rodar o MRP. A figura abaixo foi adaptada a partir do modelo proposto por Russomano (2000) e representa a configuração da função PCP na citada organização.

Figura 03 - Representação do PCP no processo de produção das havaianas da Alpargatas

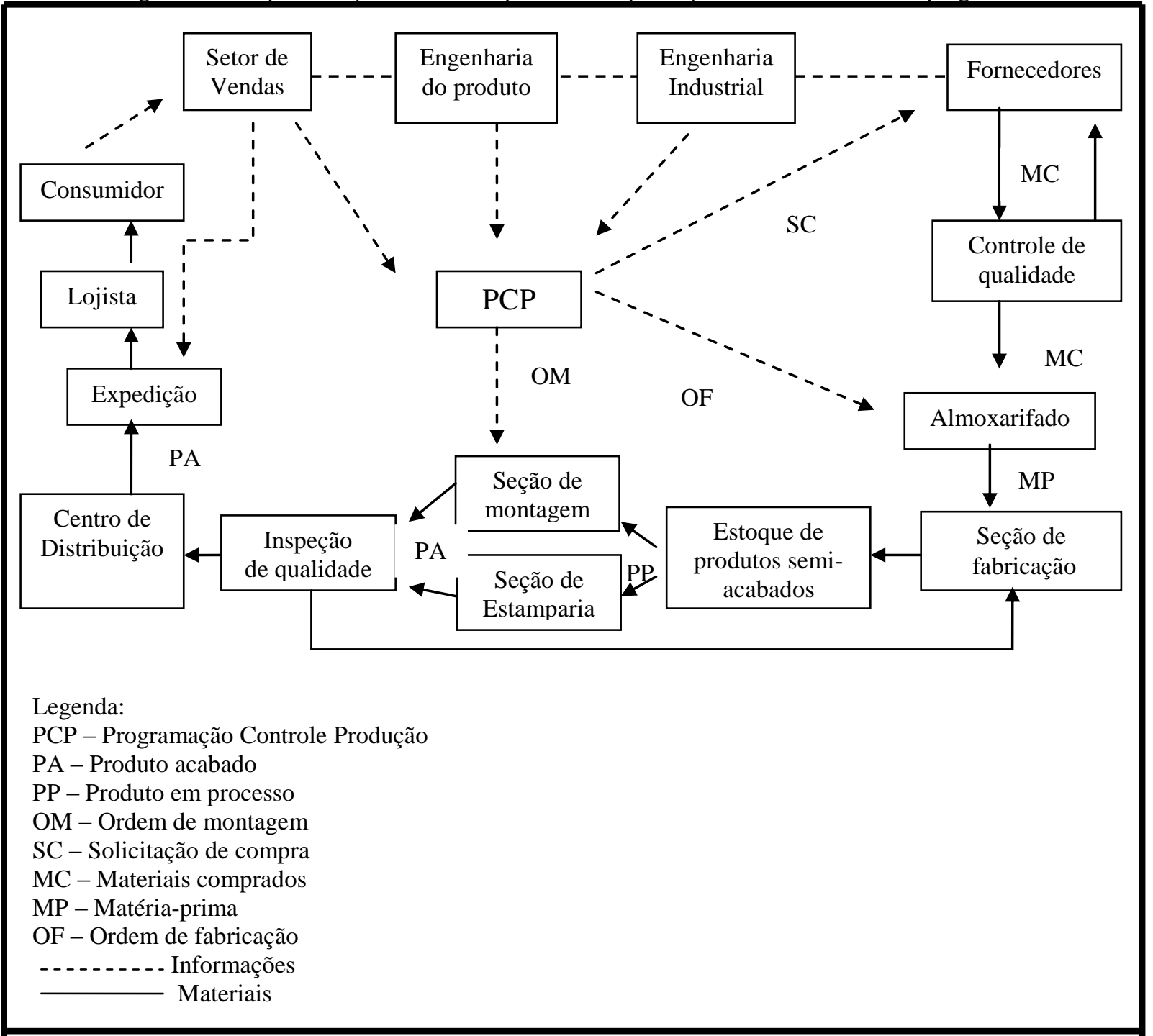

Fonte: Adaptado Russomano (2000) 
Pode-se observar, portanto, que a função PCP representa um setor independente que recebe as informações importantes principalmente do setor de vendas, engenharia do produto e industrial. Vale lembrar que, para a elaboração do plano estratégico de produção, a empresa deve ter informações de outras áreas da organização, tais como: financeiro, marketing, vendas, recursos humanos, entre outros, para planejar dentro que a empresa tem como estrutura organizacional.

Inicialmente, o PCP recebe informações do setor de vendas sobre o volume de produtos a fim de atender a demanda. Caberá também a este setor receber informações oriundas da engenharia Industrial e do Produto, já que ambas são responsáveis pelo desenvolvimento de novos produtos. Além destes, encontram-se os responsáveis pela elaboração de projetos e a função staff exercida pelo controle de qualidade.

A partir dessas informações é elaborado o planejamento mestre de produção, a fim de alocar a quantidade diária produzida para que a demanda seja atendida no prazo estabelecido, considerando o volume e a capacidade instalada do sistema produtivo. Assim, o programa mestre de produção será "a base para que se possa elaborar a programação detalhada das necessidades de materiais e de capacidade e as ordens diárias de produção" (CAVALCANTI; MORAES, 1998, p.4).

Vale salientar que, a ordem de produção inicia-se no PCP e termina quando o produto acabado (PA) dar entrada no armazém, que posteriormente é distribuído aos lojistas para assim alcançar o consumidor final.

Assim sendo, o PCP emite a ordem de fabricação que é enviada ao almoxarifado/gerência de materiais, este responsável pela compra, armazenamento e distribuição das matérias-primas as seções de trabalho após o recebimento da ordem de fabricação (OF). Para a distribuição desses materiais, o almoxarifado utiliza-se da técnica do MRP para a "explosão" do produto em suas matérias-primas e seus componentes, visto que o MRP é uma técnica para converter a previsão de demanda de um item de demanda independente (produto final) em uma programação (cálculo) das necessidades das partes componentes desse item.

Nesse momento, são gerados relatórios, a fim de verificar a real necessidade de matériaprima/componentes para o processo produtivo. Observada a necessidade de compra de matériaprima, pela indisponibilidade no almoxarifado ou não conformidade dos materiais, o PCP emite uma solicitação de compra (SC), a partir da qual o almoxarifado ficará responsável pela sua aquisição, recebimento, envio para inspeção no controle de qualidade e finalmente, o armazenamento ou devolução das peças compradas.

De posse de todos os materiais no almoxarifado necessários para o processo produtivo, o PCP emite as ordens para cada seção de trabalho autorizando o início da produção. Cada seção é autorizada de modo que nenhuma possa atrasar, haja vista que uma complementa a subsequente. 
Nesse sentido, Russomano (2000, p.222) reforça que essas ordens "determinam e autorizam a produção de uma quantidade de peças dentro de determinado prazo".

Em relação ao ambiente de produção da indústria, o mesmo é divido em dois pontos específicos para cada função, sendo o primeiro espaço destinado a transformar a matéria prima (borracha) em manta, está já saindo com a cor desejada, após isso segue para o corte de acordo com os moldes desejados. Vale lembrar que os tamanhos dos moldes é bem maior que o tamanho desejado da sandália, por exemplo, uma numeração 37 o molde é cortado em um tamanho superior 39, pois a sandália ainda tem a necessidade de voltar ao forno e daí há uma diminuição de tamanho.

Já no segundo galpão, diante de uma ordem de montagem advindas do PCP, as sandálias simples, sem estampa, segue direto para o processo de montagem, enquanto as que apresentam estampa, antes da montagem, passam pela estamparia. Nesse momento, o controle de qualidade avalia todas as sandálias diagnosticando os possíveis problemas, caso seja apresentado alguma falha, está retorna ao processo inicial.

Durante o processo produtivo observou-se a presença de um estoque de produtos semiacabado entre as seções de trabalho, estes estoques garantem o abastecimento de toda a cadeia produtiva, uma vez que "abastecem o processo subsequente, com os itens necessários, e que armazenam a produção do processo precedente" (ANDRADE, 2002, p.30-31). O estoque de fivela, uma das partes que formam as sandálias, por exemplo, são armazenadas como produtos semiacabados, uma vez que sua montagem dar-se-á em dia posterior à expedição da primeira OF.

Finalizados os processos de montagens das sandálias, os produtos acabados são disponibilizados em um armazém preparado para recebê-los. Posteriormente, esses produtos são enviados à seção de expedição onde, finalmente, são distribuídos para a cadeia lojista, alcançando, assim o consumidor final.

A função PCP da Alpargatas, unidade campinense, utiliza instrumentos (Baan, PsCom, código de barras, ordens de fabricação e montagem, dentre outros) de apoio que são periodicamente atualizados por uma equipe destinada para tal finalidade, de modo que o sistema produtivo possa ser diariamente controlado a fim de que a empresa possa honrar seus compromissos e torna-se cada vez mais competitiva no mercado.

Nesse contexto, as atividades executadas pelo PCP visam direcionar e controlar a produção para que o planejamento estratégico e, por conseguinte, o mestre seja cumprido. Segundo as informações obtidas na pesquisa de campo percebeu-se que o PCP estabelece um planejamento que possibilita um fluxo contínuo com menor setup possível, mantendo todos os setores produtivos abastecidos, a partir da quantidade de produtos que o setor de vendas planeja comercializar. 


\title{
5. Considerações finais
}

$\mathrm{O}$ atual ambiente de negócios e as crescentes exigências por parte dos consumidores têm levado as organizações a repensarem seus processos produtivos e a forma como os mesmos são administrados, de forma que o Planejamento e Controle da Produção (PCP) ganharam destaque e passou a ser um diferencial entre as empresas, tendo em vista os benefícios e os resultados satisfatórios que proporciona às mesmas.

Assim sendo, a presente pesquisa visou demonstrar sucintamente o processo de Planejamento Programação e Controle da produção de uma indústria de calçados a partir do aporte teórico adotado para a pesquisa.

Observou-se, portanto que a Alpargatas S.A, unidade campinense, apresenta um processo de planejamento, programação e controle da produção (PPCP) coerente para uma organização que tem a fabricação de sandálias como principal atividade, de forma que atende as expectativas da empresa.

Tal setor se limita a elaborar o planejamento mestre da produção, planejar e controlar a capacidade, planejar e controlar estoques, emitir ordens de fabricação, elaborar a programação e a manusear o MRP e os demais instrumentos de planejamento e controle. Por ser uma empresa de grande porte, a organização apresenta o PPCP destinado para tais finalidades, uma vez que é de sua responsabilidade o perfeito funcionamento do processo de produção.

\begin{abstract}
The current economic, political, social and environmental changes in production systems, have led organizations to rethink their way of organizing work. Thus, the production planning and control (PPC) is present to respond more quickly and precisely such changes. In this sense, the objective of this study is to describe and analyze the PPC in a shoe manufacturing industry located in Campina Grande - PB, specifically analyzing the functions of planning, programming and control of their activities. The study is characterized as exploratory and descriptive conducted in the form of case study. Data were collected through semi-structured interview with the production analyst of the firm and supplemented with secondary data and non-participant observation. The results show that the PPC developed by the firm establishes a plan that allows a continuous flow of materials, people and information, able to feed this system, in order that the productive system meets the organization's strategic goals.
\end{abstract}

Key-words: planning; production control; production management; strategy.

\section{Referências}

ABICALÇADOS. Disponível em: <"http://www.abicalcados.com.br">. Acessado na seção principal em: jul 2011.

ALPARGATAS - SP. Disponível em: http://www.alpargatas.com.br/ Acesso ago 2011.

ALves, J. M. O Sistema Just In Time Reduz os Custos do Processo Produtivo. Disponível em: <http://libdigi.unicamp.br/document/?view=32>. Acesso em: jul 2011. 
ANTUNES, J. Em Direção a uma Teoria Geral do Processo na Administração da Produção: Uma Discussão Sobre a Possibilidade de Unificação da Teoria das Restrições e da Teoria que Sustenta a Construção de Sistemas de Produção com Estoque Zero. Dissertação (Doutorado em administração de empresa) - Programa de Pós-Graduação em Administração, Universidade Federal do Rio Grande do Sul, Porto Alegre, 1998.

ANDRADE, G. J. P. O. Metodologia para a análise de viabilidade e implementação do Sistema kanban interno em malharias pertencentes a uma cadeia Produtiva têxtil. Dissertação (Mestrado em Engenharia de produção) Programa de pós-graduação em engenharia de produção, Universidade Federal de Santa Catarina, 2002.

BONNEY, M. Reflections on production planning and control (PPC). Revista Gestão \& Produção. v. 7, n. 3, p.181207, 2008.

CASSIOLATO, J.E., SZAPIRO, M.H.S. LASTRES, H.M.M., Local system of innovation under strain: the impacts of structural change in the telecommunications cluster of Campinas, Brazil. International Journal of Technology Management, v. 24, p. 680-704, 2002.

CAVAlCANTI, E. M. B.; MORAES, W. F. A. de. Programa-mestre de produção: concepção teórica x aplicação prática na indústria de cervejas e refrigerantes. ENANPAD, Florianópolis. Porto Alegre, Anais... Associação Nacional dos Programas de Pós Graduação em Administração - ANPAD, 1998. (CDROM)

CORRÊA, L. H., GIANESI, I., CAON, M., Planejamento, Programação e Controle da Produção, São Paulo : Atlas, 2007.

CORRÊA, L. H., GIANESI, I. Just-in-Time, MRP II e OPT: um enfoque estratégico, São Paulo: Atlas, 1993.

HARRISON, A. A Survival Guide to Criticai Palh Analysis and lhe Activity on Node Method. Oxford, Butterworth-Heinemann, 1997.

KEHRLE, L. Um estudo da indústria de calçados da Paraíba: uma apresentação da metodologia utilizada e do espaço de estudo. João Pessoa: UFPB/PPGE/CME, Set. 2004b. (Série Texto para Discussão n. 294).

Competitividade da indústria de calçados da Paraíba João Pessoa: UFPB/ PPGE/CME, Set. 2003. (Série Texto para Discussão n. 295).

LAURINDO, F. J. B.; MESQUITA, M. A. de. Material requirements planning: 25 anos de história - uma revisão do passado e prospecção do futuro. Revista Gestão \& Produção. Vol. 7, número 3, p.320-337, 2008.

MARTINS, P. G.; LAUGENI, F. P. Administração da Produção. São Paulo: Saraiva, 1999.

MOURA JÚNIOR, A. N. C. de. Novas Tecnologias e Sistemas de Administração da Produção - Análise do Grau de Integração e Informatização nas Empresas Catarineses. Dissertação (Mestrado em Engenharia de Produção) Universidade Federal de Santa Catarina, Florianópolis, 2006.

NAVARRO, V. L. Trabalho e Trabalhadores do Calçado. São Paulo: Editora Expressão Popular, 2006.

PIRES, S. R. I. Gestão estratégica da produção. São Paulo: Unimep, 1995.

RUSSOMANO, V. H.. Planejamento e controle da produção. 6.ed. São Paulo: Pioneira, 2000.

SLACK, N.; CHAMBERS, S.; HARLAND, C.; HARRISON, A.; JOHNSTON, R. Administração da produção. 3. ed. São Paulo: Atlas, 2008.

SERVIÇO BRASILEIRO DE APOIO ÀS MICRO E PEQUENAS EMPRESAS (SEBRAE) 2009.

TUBINO, D. F. Manual de Planejamento e controle da produção. $2^{a}$ ed. São Paulo: Atlas, 2000.

VERGARA, S. C. Projetos e Relatórios de Pesquisas e Administração. São Paulo: Atlas, 2010. 
Dados do autor:

Nome completo: Jaqueline Guimarães Santos

Filiação institucional: Universidade Federal de Pernambuco (UFPE)

Departamento: Programa de Pós Graduação em Administração (PROPAD)

Função ou cargo ocupado: Estudante de Mestrado em Administração

Endereço completo para correspondência: Rua Edgar Bezerra Lopes, 30, Apto 401, Várzea, CEP: 50740-420 Recife - PE, Brasil.

Telefones para contato: (83) 9176-6684/ (81) 3034-9088.

e-mail: jsantos.adm@gmail.com

Submetido em: 07/05/2012

Aceito em: 30/09/2013 